\title{
Two cases of ocular sarcoidosis in which vitreous cytology was useful for supporting the diagnosis
}

This article was published in the following Dove Press journal:

Clinical Ophthalmology

30 July 2012

Number of times this article has been viewed

\author{
Masato Matsuoka' \\ Nahoko Ogata ${ }^{2}$ \\ Kanji Takahashi ${ }^{3}$ \\ Yuichi Kinoshita ${ }^{4}$ \\ Tetsuya Nishimura' \\ 'Department of Ophthalmology, \\ Kansai Medical University, Takii \\ Hospital, Osaka, ${ }^{2}$ Department \\ of Ophthalmology, Nara Medical \\ University, Nara, ${ }^{3}$ Department of \\ Ophthalmology, Kansai Medical \\ University, Hirakata Hospital, Osaka, \\ ${ }^{4}$ Department of Histopathology, \\ Kansai Medical University, \\ Takii Hospital, Osaka, Japan
}

\begin{abstract}
The purpose of this paper is to report two cases of sarcoidosis with conflicting signs in which vitreous cytology was useful for supporting the diagnosis. Case 1 was a 56-year-old man who was referred with blurred vision, and was found to have iridocyclitis, vitreous opacities, and optic neuritis bilaterally. He also had a swelling of both mandibular glands. He received pulsed corticosteroid therapy, but the vitreous opacities and papilledema did not resolve. The second case was a 77-year-old man referred with blurred vision, and both eyes had snowballlike vitreous opacities and optic neuritis. The ocular findings in both cases strongly suggested sarcoidosis, but the systemic findings did not meet the diagnostic criteria for sarcoidosis. We performed pars plana vitrectomy to remove the vitreous opacities, and the collected vitreous samples were sent for cytological analyses. Epithelioid and multinucleated giant cells pathognomonic of sarcoidosis were found in the vitreous samples which enabled us to make a diagnosis of sarcoidosis. Vitreous cytology can help in supporting a diagnosis of sarcoidosis, especially in cases of ocular inflammation suggesting sarcoidosis but systemic findings that do not satisfy the diagnostic criteria for this disease.
\end{abstract}

Keywords: sarcoidosis, cytology, vitreous, pars plana vitrectomy, papilledema

\section{Introduction}

A recent epidemiological study of intraocular inflammation in Japan reported that sarcoidosis is the most prevalent uveitis. ${ }^{1}$ However, many of the cases do not meet the diagnostic criteria of sarcoidosis because of lack of systemic signs. ${ }^{2,3}$ We report two cases of ocular inflammation whose vitreous cytology supported the diagnosis of sarcoidosis.

\section{Case report I}

A 56-year-old man was referred to our hospital with blurred vision in his right eye in April 2008. On initial examination, his corrected visual acuity was 20/20 in both eyes. The anterior chamber was mildly inflamed, but dense vitreous opacities were present in his right eye and optic neuritis was present bilaterally (Figure 1A and B). Fluorescein angiography showed dye leakage from both optic discs (Figure 1C and D). The results of laboratory examinations were essentially normal, including serum levels of angiotensin-converting enzyme, calcium, gammaglobulin, anti-human T lymphotropic virus-1 antibody, anti-herpes simplex virus antibody, and anti-varicella zoster virus antibody. The patient was weakly positive for tuberculin. A chest x-ray did not show bilateral hilar lymphadenopathy. Examinations according to the criteria
Correspondence: Nahoko Ogata Department of Ophthalmology, Nara Medical University, 840 Shijo-cho, Kashihara, Nara 634-8522, Japan

Tel +81744298884

$\mathrm{Fax}+81744238032$

Email ogata@takii.kmu.ac.jp 

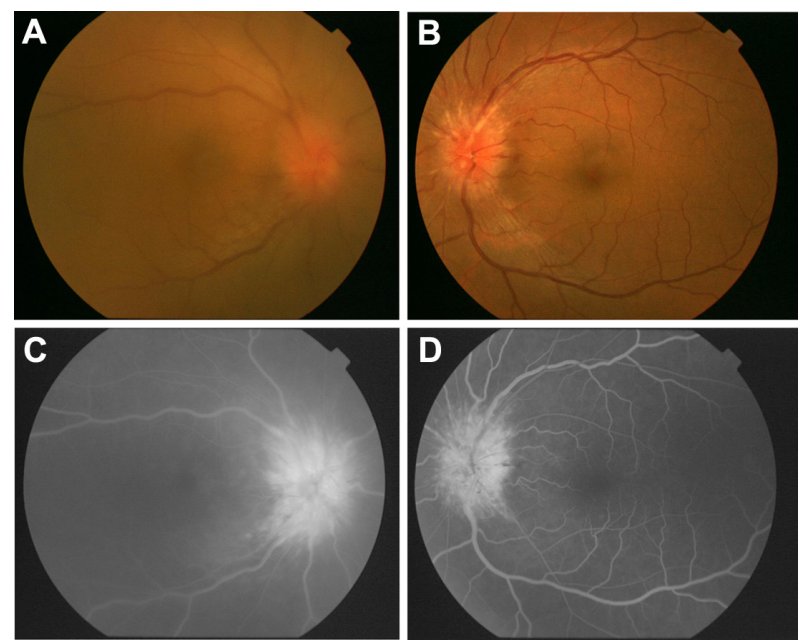

Figure I Fundus photographs and fluorescein angiograms for case I with sarcoidosis. (A and B) Fundus photographs of right and left eye at initial examination. Diffuse vitreous opacities can be seen in the right eye and optic neuritis in both eyes. (C and D) Fluorescein angiograms showing dye leakage from the optic discs of both eyes. (A and $\mathbf{C}$ ), right eye, (B and D) left eye.

for sarcoidosis were negative and tuberculosis was ruled out by our Department of Internal Medicine. His visual acuity had decreased to 20/100 OD, with increased numerous snowballlike vitreous opacities, and mutton-fat keratic precipitates and nodules were observed in the anterior chamber angles. Therefore, he underwent pars plana vitrectomy with a 25 gauge system to remove the dense vitreous opacities, and diluted and undiluted vitreous was obtained to determine the cause of the inflammation. Histiocytes, and epithelioid and multinucleated giant cells were detected by cytology in diluted vitreous samples, but necrotic materials and malignant cells were not detected (Figure 2). He received systemic corticosteroid therapy, and 2 months after surgery, optic neuritis was reduced and his corrected visual acuity had improved to 20/20 OD.

\section{Case report 2}

A 77-year-old man was referred to our hospital with blurred vision in May 2009. He was diagnosed with lung small cell carcinoma in October 2008, and received chemotherapy from December 2008 at our Department of Internal Medicine.

On initial examination, his corrected visual acuity was $20 / 20$ OD and 20/25 OS. The anterior chamber was not inflamed, but numerous snowball-like vitreous opacities, optic neuritis, and periphlebitis were observed in both eyes (Figure 3A and B). Fluorescein angiography showed dye leakage from the optic discs and along the retinal veins in both eyes (Figure 3C and D).

The results of laboratory examinations were essentially normal. Neuron-specific enolase, progastrin-releasing peptide,

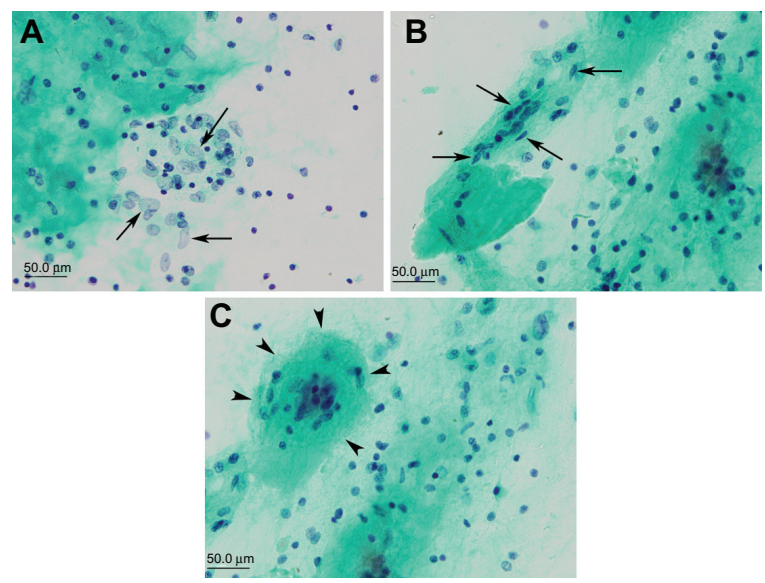

Figure 2 Vitreous cytology for case I with sarcoidosis. (A) Histiocytes (arrows), (B) epithelioid cells (arrows), and (C) multinucleated giant cells (arrowheads) can be seen.

Note: Necrotic materials and malignant cells are not present on Papanicolaou staining.

and markers of lung small cell carcinoma were normal in the serum. The patient was weakly positive for tuberculin. A chest $x$-ray did not show bilateral hilar lymphadenopathy. A computed tomography scan of the chest showed that the original focus of the lung small cell carcinoma had disappeared after chemotherapy. Cerebral magnetic resonance did not detect any abnormalities. Thus, the attending physician considered that the probability of metastasis was low. Examinations according to the criteria of sarcoidosis were negative, and tuberculosis was ruled out, as in case 1.

The vitreous opacities in both eyes had increased a month later, and his corrected visual acuity was reduced to 6/20 OD and 6/10 OS. Therefore, he underwent pars plana

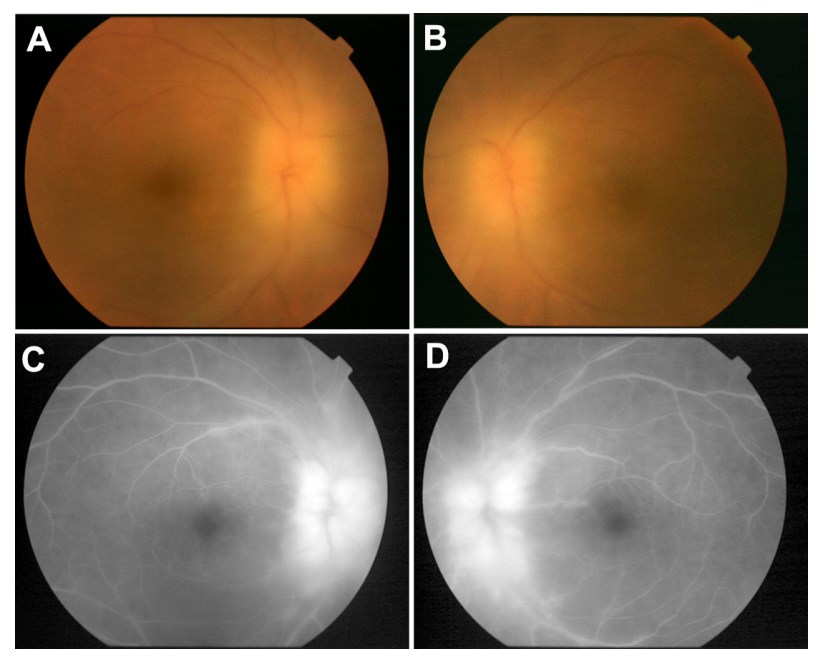

Figure 3 Fundus photographs and fluorescein angiograms for case 2 with sarcoidosis. (A and B) Fundus photographs taken at the initial examination. Numerous snowballlike vitreous opacities and optic neuritis can be seen in both eyes. (C and D) Fluorescein angiograms showing dye leakage from the optic discs and along the retinal veins in both eyes. (A and $\mathbf{C}$ ) right eye, (B and $\mathbf{D})$ left eye. 
vitrectomy on both eyes. Vitreous samples were obtained as in case 1. Epithelioid and multinucleated giant cells were found by vitreous cytology (Figure 4). Necrotic materials and malignant cells were not detected. Because of his poor condition, he received a posterior sub-Tenon injection of triamcinolone acetonide in both eyes instead of systemic corticosteroid therapy. One month after pars plana vitrectomy, the optic neuritis was resolved and corrected vision had improved to 20/20 OD.

\section{Discussion}

The histological finding of sarcoidosis is a noncaseating granuloma consisting of epithelioid and multinucleated giant cells by biopsy. ${ }^{2}$ However, a biopsy of intraocular tissues is generally not performed because of the risk of

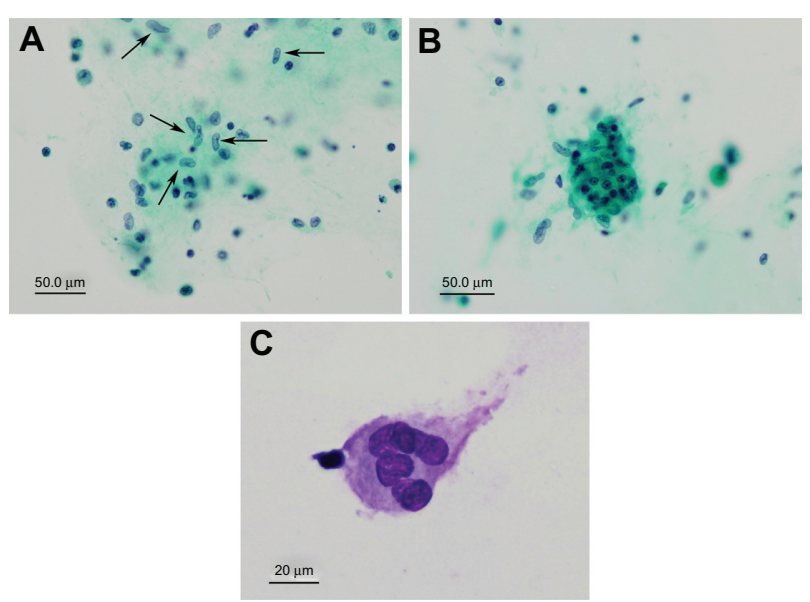

Figure 4 Vitreous cytology for case 2 with sarcoidosis. (A) epithelioid cells (arrows), and (B and $\mathbf{C}$ ) multinucleated giant cells can be seen. Necrotic materials and malignant cells are not present. (A and B) Papanicolaou staining, (C) Giemsa staining. visual complications. ${ }^{4}$ In addition, the intraocular tissues obtained are usually very small which makes it difficult to examine them by histological sections.

We collected all of the diluted vitreous during pars plana vitrectomy and submitted it for cytological analysis. Undiluted vitreous with high viscosity is not effective for collecting cells by cytospin, but diluted vitreous with low viscosity was effective. This may be the reason why we detected epithelioid and multinucleated giant cells, although a previous report had failed to find these cells. ${ }^{5}$ We found that surgical removal of the vitreous was effective in restoring visual acuity, and vitreous cytology can be useful to support the diagnosis of sarcoidosis in patients whose eyes are considered to have sarcoidosis but systemic findings do not satisfy the diagnostic criteria.

\section{Disclosure}

The authors report no conflicts of interest in this work.

\section{References}

1. Goto H, Mochizuki M, Yamaki K, et al. Epidemiological survey of intraocular inflammation in Japan. Jpn J Ophthalmol. 2007;51:41-44.

2. Ishihara $\mathrm{M}$, Ohara $\mathrm{K}$, Usui $\mathrm{M}$, et al. Diagnostic standard and guideline for sarcoidosis - 2006. Nippon Ganka Gakkai Zasshi. 2007;111:117-121. Japanese.

3. Shibuya E, Ishihara M, Nakamura S, Hayashi K, Mizuki N. Diagnosis of sarcoidosis from ocular findings based on revised version of diagnostic guidelines for sarcoidosis. Rinsho Ganka. 2009;63:1917-1922. Japanese.

4. Kvanta A, Seregard S, Kopp ED, All-Ericsson C, Landau I, Berglin L. Choroidal biopsies for intraocular tumors of indeterminate origin. Am J Ophthalmol. 2005;140:1002-1006.

5. Wittenberg LA, Maberley DA, Ma PE, Wade NK, Gill H, White VA. Contribution of vitreous cytology to final clinical diagnosis fifteen-year review of vitreous cytology specimens from one institution. Ophthalmology. 2008;115:1944-1950.
Clinical Ophthalmology

\section{Publish your work in this journal}

Clinical Ophthalmology is an international, peer-reviewed journal covering all subspecialties within ophthalmology. Key topics include: Optometry; Visual science; Pharmacology and drug therapy in eye diseases; Basic Sciences; Primary and Secondary eye care; Patien Safety and Quality of Care Improvements. This journal is indexed on

\section{Dovepress}

PubMed Central and CAS, and is the official journal of The Society of Clinical Ophthalmology (SCO). The manuscript management system is completely online and includes a very quick and fair peer-review system, which is all easy to use. Visit http://www.dovepress.com/ testimonials.php to read real quotes from published authors. 